\title{
Habitat choice in the Drosophila affinis subgroup
}

\author{
Jody Hey and \\ David Houle
} Department of Ecology and Evolution,
State University of New York at Stony Brook,
Stony Brook, New York 11794, U.S.A.

We investigated habitat choice in three species of Drosophila in seven mark-release-recapture experiments. We captured and recaptured flies in two floristically distinct habitats, and released them on the ecotone between the two. We recovered a total of $\mathbf{3 8 0 0}$ marked flies. $\boldsymbol{D}$. affinis males consistently showed a slight, significant tendency to return to the habitat of capture. $D$. athabasca, algonquin, and $D$. affinis females showed no significant habitat fidelity, but did not choose differently from affinis males. Our data suggests that the choice observed is not due to differences in the physiological condition of the flies. The level of choice observed is probably too small to have an appreciable impact on gene frequencies.

\section{INTRODUCTION}

Drosophila species have long been favored targets for studies of genetic structure in natural populations. Consequently, their dispersal ability has been extensively studied, under the simplifying assumption of essentially random movement (e.g., Crumpacker and Williams, 1973). Microgeographic genetic differentiation between habitats which may be inconsistent with such a model has been found in $D$. persimilis (Taylor and Powell, 1977), and D. melanogaster (Stalker, 1976). In both cases, if dispersal was random, very powerful selection would be necessary to maintain the observed differentiation. Taylor and Powell (1978) proposed habitat choice and weaker selection as an alternative explanation. They showed that $D$. pseudoobscura and $D$. persimilis captured in adjacent patches of wet, dark woods and dry, light woods tended to return to the kind of habitat in which they were captured in mark-release-recapture experiments.

Subsequent attempts to repeat Taylor and Powell's observations have led to mixed results. Atkinson and Miller (1980) failed to find habitat choice in $D$. subobscura captured in two open areas and adjacent closed canopy woods. Shorrocks and Nigro (1981) did find significant choice in $D$. subobscura at the same site. The two experiments differed in the particular patches of habitat used for capture and recapture. Kekic et al. (1980) also reported significant choice in $D$. subobscura, in a similar, but small, series of experiments. Turelli et al. (1984) studied habitat choice of Drosophila between orchards containing different species of fruit trees, so that the resources important to flies in different areas were clear. Three releases of a mixture of $D$. melanogaster and $D$. simulans turned up significant, but very weak choice. $D$. pseudoobscura, however, showed significant aversion to the habitat where they were captured in a smaller experiment in the same orchard.

These authors supposed that any differences in choice behavior were adaptive responses to a patchy environment. Hoffmann and Turelli (1985) suggested an alternative. They compared the relative attractiveness of two kinds of baits for labreared $D$. melanogaster. One group of flies was allowed to feed until release, while other groups of flies were starved for 12 or 24 hours. In all three tests, the unstarved flies had a higher probability of being captured at the higher quality bait than the starved flies. They suggest that flies in poor physiological condition may be less able or willing to discriminate among resources. If flies captured in different habitats also differ in physiological condition, the previous observations of choice could be due to the inability of one group of flies to take advantage of positive environmental cues. If this physiological explanation for habitat choice 
is general, the potential genetic consequences are slight.

We report here the results of seven habitat choice experiments with three closely related species of the D. affinis subgroup. We find evidence for consistent, weak habitat choice in one of the species we studied.

\section{METHODS}

All experiments were conducted at the Edmund Niles Huyck Preserve in Rensselaerville, New York, U.S.A. The Preserve is an area of 570 hectares, consisting primarily of second growth forest.

We studied three common species of woodland flies: Drosophila affinis, $D$. athabasca, and $D$. algonquin. All are in the affinis subgroup of the obscura group. Individual flies can be identified to species and sex on the basis of morphology, except that $D$. affinis and $D$. algonquin females cannot be distinguished. We refer to these flies as affinis/algonquin females. This population of $D$. athabasca is made up of the semispecies "Eastern A", with very few or none of the other semispecies present, based on the semispecies' geographic distributions, and our observations of karyotypes (Miller and Westphal, 1967), and genotypes at three allozyme loci (Jaenike, et al., 1978; Johnson, 1978, 1985).

In each experiment we captured flies in two adjacent habitats, marked each group with micronised fluorescent dust, and then released them in the ecotone between the habitats. Flies were recaptured in each habitat and examined under UV light for markings. The flies were marked by placing a small amount of dust in a vial with the flies and agitating the vial. We captured flies by netting them from $2 \frac{1}{2}$ or 5 gallon plastic buckets containing fermented banana mash. Baits were reallocated at random to the different habitats between capture and recapture periods. In the warm summer months, these species are most active in the midmorning and evening, so times and recapture effort are expressed in terms of the number of these morning and evening activity periods.

We conducted seven experiments over two summers. Details of each experiment are provided in table 1 . In experiments 1 through 5 we captured and recaptured flies in patches of forest dominated by hemlock (Tsuga canadensis) or by a mixture of deciduous tree species, of which sugar maple (Acer saccharum) was usually most abundant. The hemlock areas are darker, have less understory vegetation, lower daytime temperatures, and high humidity than the decidious areas.

Experiments 1 and 3 were carried out in an old, 8 hectare hemlock stand and the surrounding deciduous area. At the release point, the ecotone between the two was about $20 \mathrm{~m}$ wide. In both of these experiments we simultaneously estimated dispersal of the flies. For recapture, baits were placed $40 \mathrm{~m}$ apart on transects extending into each habitat.

Flies released in experiment 1 were handled in one of two ways. "Handled" flies were collected from three days before release to the morning before release. All of these flies were anaesthetised with $\mathrm{CO}_{2}$, identified to species and sex, and counted prior to marking. All flies which died in captivity were also counted. "Unhandled" flies were captured one-half hour to 2 hours before marking and release. Contingency table analysis showed that no interactions including handling as a factor

Table 1 Characteristics of experiments

Experiments

\begin{tabular}{|c|c|c|c|c|c|c|}
\hline \multicolumn{5}{|c|}{ Hemlock vs. deciduous } & \multicolumn{2}{|c|}{ Pine vs. mixed } \\
\hline 1 & 2 & 3 & 4 & 5 & wild files & lab-reared \\
\hline $8 / 20 / 83$ & $8 / 24 / 83$ & $7 / 9 / 84$ & $7 / 11 / 84$ & $7 / 14 / 84$ & $7 / 14 / 84$ & $9 / 11 / 84$ \\
\hline 7:00 pm & $9: 20 \mathrm{am}$ & $7: 30 \mathrm{pm}$ & $8: 15$ am & $9: 30 \mathrm{am}$ & $9: 30 \mathrm{am}$ & $10: 00 \mathrm{am}$ \\
\hline no & yes & no & no & yes & yes & no \\
\hline 23 & 16 & 20 & 23 & 24 & 24 & 19 \\
\hline 82 & 24 & 2 & 24 & 24 & 24 & - \\
\hline $8 / 21 \mathrm{pm}$ & $8 / 24$ am & $7 / 10 \mathrm{pm}$ & $7 / 11 \mathrm{am}$ & $7 / 14 \mathrm{am}$ & $7 / 14 \mathrm{am}$ & 9/11 pm \\
\hline $8 / 22 \mathrm{am}$ & $8 / 24 \mathrm{pm}$ & $7 / 12 \mathrm{pm}$ & $7 / 11 \mathrm{pm}$ & $7 / 14 \mathrm{pm}$ & $7 / 14 \mathrm{pm}$ & $9 / 12 \mathrm{am}$ \\
\hline- & - & - & $7 / 12 \mathrm{am}$ & - & - & - \\
\hline 51 & 20 & 66 & 60 & 30 & 60 & 50 \\
\hline
\end{tabular}


are significant; so only the combined recapture data are presented.

During experiment 3 , flies which were not marked as to their habitat of origin were released on July 7, as part of the concurrent study of dispersal. Many of these flies were recaptured, marked, and released again on July 9, along with previously unmarked flies. Twice-marked affinis males were recaptured in sufficient numbers for analysis.

Experiments 2 and 5 were carried out in a younger 0.7 hectare stand of hemlock and the surrounding deciduous area dominated by Betula lutea and $B$. papyrifera, between which the ecotone was very sharp. The flies used in these experiments were captured in several other locations, so any habitat choice observed would have been due to general characteristics of each habitat, rather than area specific ones. The number of flies released was not estimated in either case. Recapture baits were scattered 10 to $50 \mathrm{~m}$ from the release point.

The release for experiment 4 was made on the bank of a small stream that followed a sharp ecotone between a hemlock stand and a mixed deciduous stand. Baits were evenly spaced between ten and $100 \mathrm{~m}$ of the release point.

The "wild pine" and "lab-reared" experiments were conducted in a 50 year old Pinus resinosa plantation and an adjacent patch of mixed hemlock and deciduous woods. The pine plantation contained no understory vegetation, and was slightly lighter than the mixed woods. We placed baits in rectangular arrays 20 to $50 \mathrm{~m}$ from the release point. For the "wild pine" experiment we used wild captured flies. Following this experiment, we returned about 100 unmarked affinis/algonquin females from each area to the lab. The $F_{1}$ progeny of these flies were reared (Hey and Houle, 1985), and the affinis sibships were released in the "lab-reared" experiment.

Flies awaiting release were held on an agarsugar medium in 1983 and a complete medium (Hey and Houle, 1985) in 1984. The number of flies released was estimated in most experiments by withholding about ten percent of the flies captured from the release. In experiment 1 , most captured flies were anaesthetized with $\mathrm{CO}_{2}$ and counted before release.

Heterogeneity in the behavior of released flies was tested by multi-way contingency table analysis (Bishop et al., 1975). Goodness of fit was assessed using the likelihood ratio statistic $\left(G\right.$, or $\left.G^{2}\right)$. The computations were carried out using the "Catmod" procedure of SAS (SAS Institute, Inc., 1985).

The simplest model which fit the data was found by backwards selection. First we fit the most complicated model possible. The highest order terms in the model were then deleted until none of the remaining terms could be deleted without causing a significant increase in $G$, or causing $G$ for the full model to rise above the critical value for $P=0.05$. We represent a significant interaction between factors $A$ and $B$ as [ $A B]$. The significance of each interaction term can be individually assessed by examining the significance of the change in $G$ when terms in the "simplest" model are subtracted, or terms not in the "simplest" model are added. The significance of a high order interaction implies the presence in the model of all lower order interactions between those factors, including the main effects.

In this study, we define "habitat choice" as a tendency for marked flies to return to (or avoid) the habitat in which they were captured. Under this definition, the presence of a capture site by recapture site interaction term $([\mathrm{CR}])$ indicates significant habitat choice. The significance of this term is dependent on both the magnitude of the interaction and the sample size. The magnitude of habitat choice is of particular interest here. Turelli et al. (1984) devised a choice index to quantify this for two by two tables. Turelli's choice index, $\Delta$, is equal to $P_{X \mid X}-P_{X \mid Y}$, or the probability that a fly chose habitat $X$ given that it originally came from $X$, minus the probability that a fly chose habitat $X$ given that it originally came from $Y$. This index ranges between -1 and +1 .

\section{RESULTS}

The results of the seven experiments are shown in tables 2-4. In many cases, not enough flies were recaptured in each of the species/sex classes to allow analysis. The results of contingency table analysis for each experiment are shown in table 5 . The capture site by recapture site interaction term ([CR]) is significant in three of the eight cases, providing evidence for habitat choice.

In experiment $1,[C R]$ is retained in the simplest model. When [CR] is dropped it results in an insignificant increase in $G$, but the model ceases to fit by the $P=0.05$ criterion $(G=23 \cdot 80$, $14 \mathrm{df}$ ). This is weak evidence for habitat choice. However, several observations indicate that the hemlock and deciduous flies in this experiment differed in physiological condition. In all cases, the flies captured in the deciduous area were more likely to be recaptured than those captured in the hemlock area (table 2). Hemlock flies had roughly twice the mortality of deciduous flies while in 
Table 2 Capture and recapture data for experiment 1. For explanation of the handling of the flies, see text. Mortality is expressed as a percentage of those released

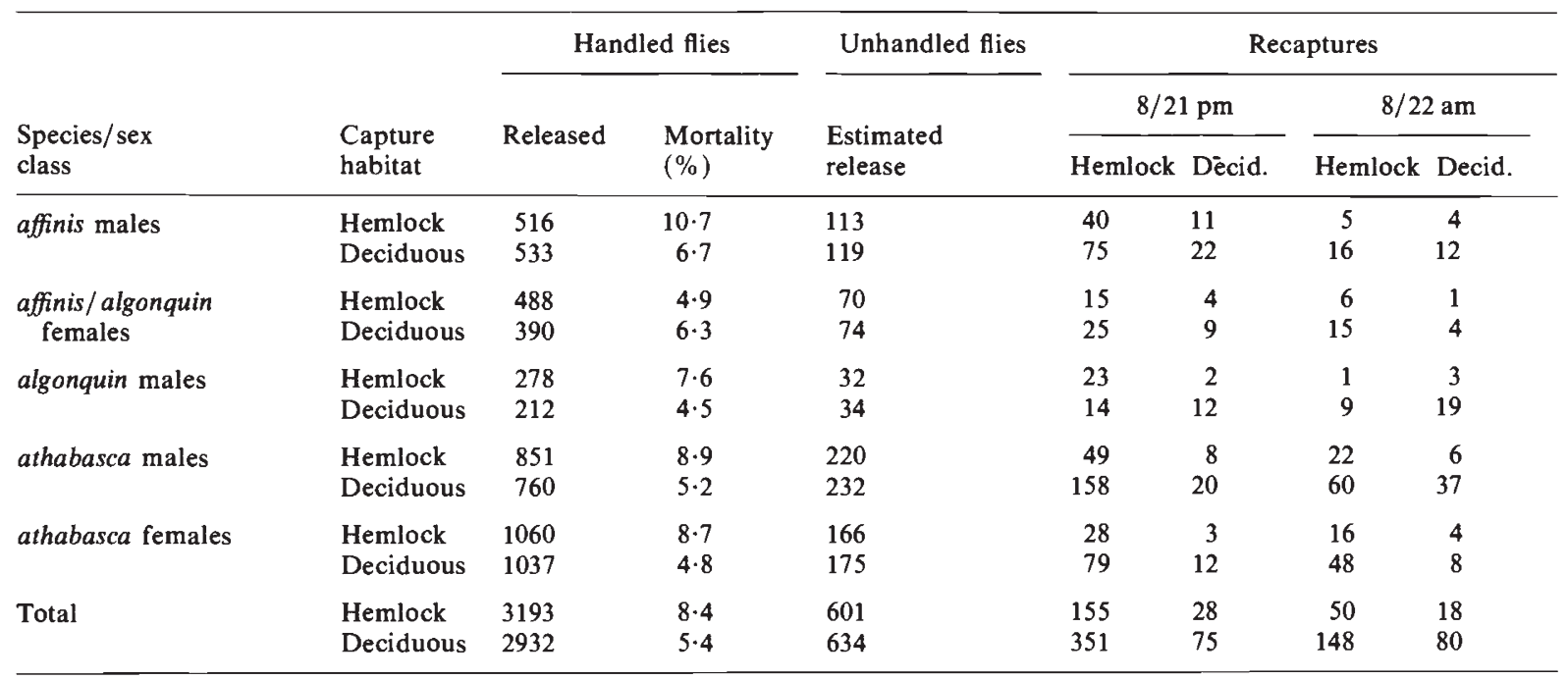

Table 3 Release and recapture data for experiments 2-5

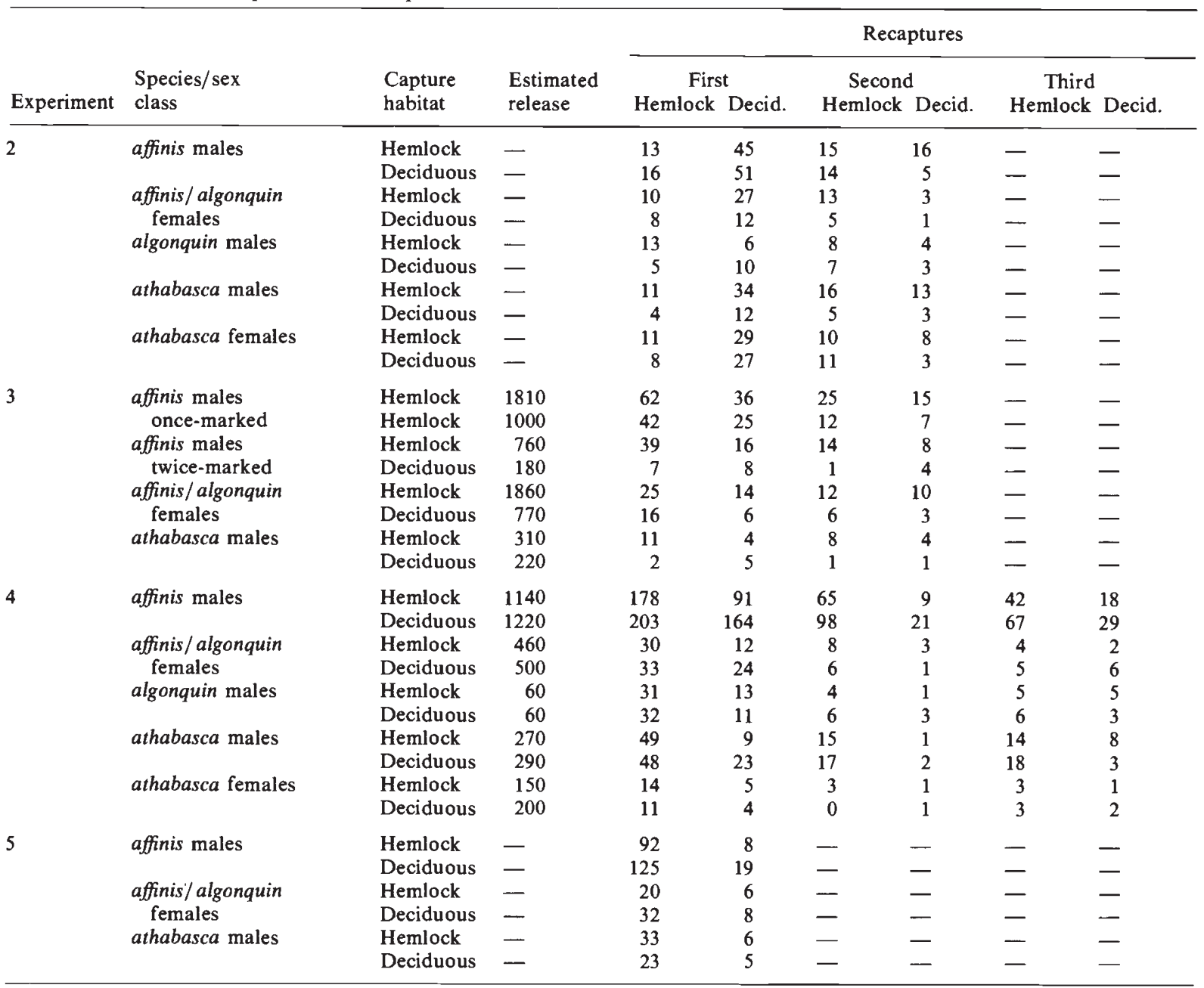


Table 4 Number of flies released and recaptured in the pine plantation experiments. For the lab-reared flies, "capture habitat" refers to the site where the parents were captured

\begin{tabular}{|c|c|c|c|c|c|c|c|}
\hline Experiment & $\begin{array}{l}\text { Species/sex } \\
\text { class }\end{array}$ & $\begin{array}{l}\text { Capture } \\
\text { habitat }\end{array}$ & $\begin{array}{l}\text { Estimated } \\
\text { release }\end{array}$ & \multicolumn{4}{|c|}{ Recaptures } \\
\hline \multirow[t]{2}{*}{ Wild flies } & \multirow[t]{2}{*}{ affinis males } & Pine & 460 & 17 & 27 & 11 & 24 \\
\hline & & Mixed & 300 & 8 & 34 & 4 & 18 \\
\hline \multirow[t]{4}{*}{ Lab-reared flies } & \multirow[t]{2}{*}{ affinis males } & Pine & 600 & 14 & 13 & 1 & 2 \\
\hline & & Mixed & 725 & 16 & 13 & 8 & 4 \\
\hline & \multirow[t]{2}{*}{ affinis females } & Pine & 600 & 3 & 5 & 0 & 5 \\
\hline & & Mixed & 725 & 7 & 5 & 4 & 3 \\
\hline
\end{tabular}

captivity (change in $G$ when the capture site by mortality interaction is dropped $=24 \cdot 10$, $\mathrm{df}=1$, $P<0.0001)$. Among "handled" flies, hemlock flies traveled about 25 per cent less far in the 24 hours between release and the first recapture period than did the deciduous flies, while there were no consistent dispersal differences due to capture site mong "unhandled" flies (Houle and Hey, unpublished). This suggests that there may have been physiological differences between the groups of flies, and that "handled" hemlock and deciduous flies may have been affected differently by captivity.

Fig. 1 shows the choice index, $\Delta$, with 95 per cent confidence limits for each fly class in each experiment. In order to calculate $\Delta$, the data were first collapsed over time of recapture. In three cases, shown by asterisks, interactions of time of recapture with capture site and recapture site make this collapse inappropriate. In these cases, $\Delta$ was calculated from the first recapture only.

We examined the patterns of choice exhibited by each species/sex class over the experiments using wild flies, excluding experiment 1 , using the data collapsed for time of recapture. These analyses all have experiments (E), capture site, and recapture site as factors. Affinis males are fit by [CR], [EC], [ER]. The [CR] term is significant at $P<0.005(G=9.86,1 \mathrm{df})$. For three of the six releases, $\Delta$ is significantly greater than 0 , but the level of preference for the habitat of capture is low. The average $\Delta$ value, weighted by total sample size, is 0.076 . The recapture period in experiment 2 that was dropped because of time interactions had a $\Delta$ value of $-0.25 \pm 0 \cdot 27$, which is close to significance $(G=3 \cdot 18,1 \mathrm{df}, P<0 \cdot 1)$. In spite of this, even if these data are included, the $[C R]$ term is still significant across all five experiments.

In spite of the fact that the first recapture of athabasca males in experiment 4 shows a significant $\Delta$ value, analysis of all five experiments shows that the model [EC], [ER] fits adequately. Adding the $[C R]$ term decreases $G$ by $1.86(1 \mathrm{df}$, $P<0.5)$. The two recapture periods of experiment 4 dropped from the above analysis have insignificant $\Delta$ values $(0 \cdot 043 \pm 0 \cdot 19$, and $-0 \cdot 22 \pm 0 \cdot 26)$.

Table 5 Results of contingency table analysis of recapture data for each experiment. "Model" is the simplest log-linear model which fits the data at $P>0.05$. The $G$ value shown for the capture-site by recapture site interaction is the change in $G$ when that term is added to or subtraced from the simplest model

\begin{tabular}{|c|c|c|c|}
\hline Experiment & Factors $\dagger$ & Model & $\begin{array}{l}G \text { for capture- } \\
\text { recapture interaction }\end{array}$ \\
\hline 1 & C R S T & {$[\mathrm{STR}],[\mathrm{SC}],[\mathrm{TC}],[\mathrm{CR}]$} & $3 \cdot 17$ \\
\hline 2 & C R S T & {$[\mathrm{SC}],[\mathrm{SR}],[\mathrm{TR}]$} & 0.02 \\
\hline 3 singly-marked & C RST & {$[\mathrm{C}],[\mathrm{R}],[\mathrm{S}],[\mathrm{T}]$} & $0 \cdot 30$ \\
\hline 3 doubly-marked & C R T & {$[\mathrm{CR}],[\mathrm{T}]$} & $5 \cdot 49 *$ \\
\hline 4 & C R S T & {$[\mathrm{CR}],[\mathrm{TR}],[\mathrm{SR}]$} & $8 \cdot 24^{* *}$ \\
\hline 5 & C R S & {$[\mathrm{C}],[\mathrm{R}],[\mathrm{S}]$} & 0.70 \\
\hline Pine & C R S T & {$[\mathrm{CR}],[\mathrm{S}],[\mathrm{T}]$} & $6 \cdot 86^{* *}$ \\
\hline $\mathrm{Lab} \ddagger$ & C R S & {$[\mathrm{C}],[\mathrm{R}],[\mathrm{S}]$} & $2 \cdot 73$ \\
\hline
\end{tabular}

$\ddagger \mathrm{C}=$ Capture site, $\mathrm{R}=$ Recapture site, $\mathrm{S}=$ Species/sex class, $\mathrm{T}=$ Time of recapture.

$\ddagger$ Data collapsed over times before analysis, because of low sample size.

${ }^{*} \boldsymbol{P}<0.05,{ }^{* *} \boldsymbol{P}<0.01$. 

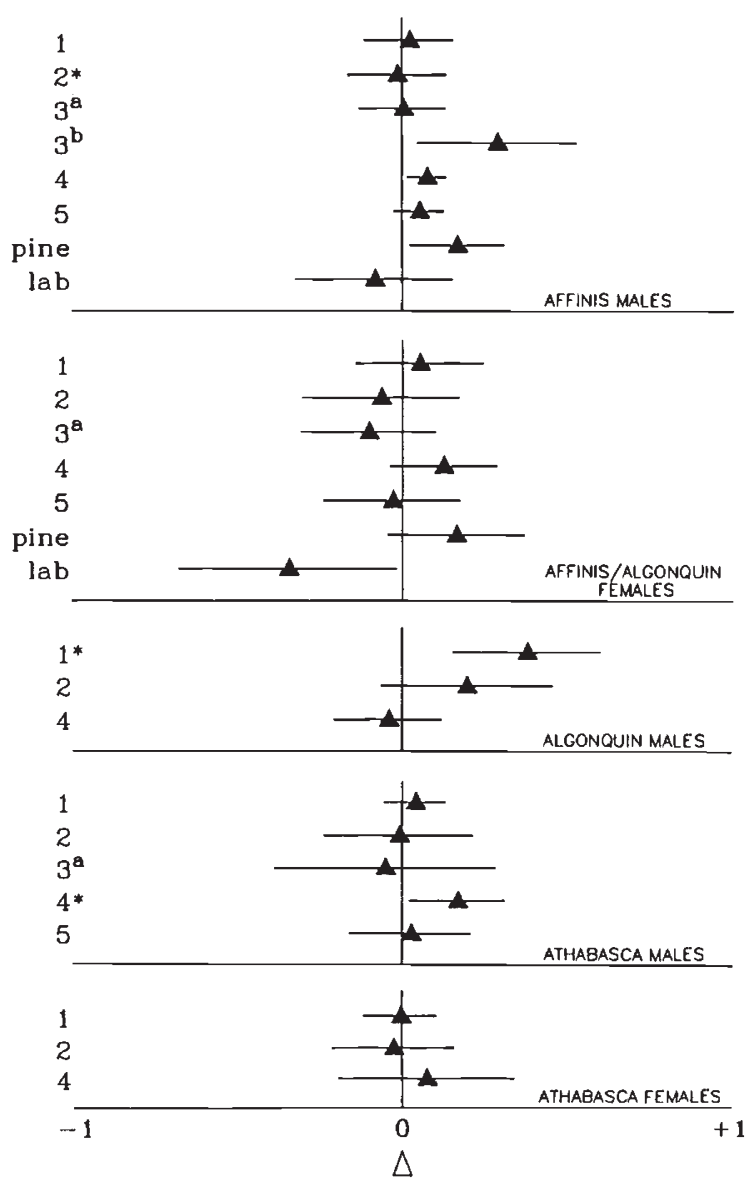

Figure 1 Choice indices, $\Delta$, for each species/sex class in each experiment, \pm 95 per cent confidence limits. Asterisks denote that only data from the first recapture period was used to calculate $\Delta$. "a" denotes once captured flies, and "b" twice-captured flies from experiment 3 .

No other class of flies shows any evidence of habitat choice in these experiments. Algonquin males are fit by the model [E], [R]. Adding [CR] decreases $G$ only $0.23 \quad(2 \mathrm{df}, \quad P>0.5)$. Affinis/algonquin females are fit by [EC], [ER], and adding [CR] decreases $G$ by $0.48(1 \mathrm{df}, P<$ $0 \cdot 5)$. Athabasca females are fit by [ER], and adding [CR] decreases $G$ by 1.22 ( $2 \mathrm{df}, P>0.5)$.

The "lab-reared" experiment was designed to test whether habitat preference is heritable. The parental generation showed significant habitat choice, while the lab-reared flies did not. When we collapse the data over time of recapture and analyse the two releases together we obtain the model [ECR], [S]. The [ECR] term is highly significant $(G=8.90,1 \mathrm{df}, P<0.005)$. The lab-reared flies chose less than the parental generation. Thus we have no evidence that habitat preference is heritable.

The $\Delta$ values for all groups except algonquin males are highly correlated with each other. These correlations are shown in table 6. Three of the six correlations between affinis and athabasca classes are significantly greater than 0 , even with the small sample sizes involved.

\section{DISCUSSION}

Habitat choice, defined as a tendency for marked flies to return to the area in which they were captured, might be observed for several reasons. Taylor and Powell (1978) supposed that habitat choice was an adaptive response to spatially heterogeneous selective regimes. Under this hypothesis, choice behaviour could result from a genetic polymorphism for habitat preference, or from a general tendency for flies to prefer habitats in which they have previous experience. In either case, habitat choice could facilitate genetic differentiation between habitats. Hoffmann and Turelli (1985) have proposed that the ability to discriminate the quality of resources may vary with the physiological state of flies. Fies which differ in their discrimination may then differ in their behaviour. This is unlikely to affect genetic differentiation.

When our experiments were performed we were unaware of Hoffmann and Turelli's (1985) results showing that starved flies are less likely to choose the better of two resources. Fortunately, the physiological condition hypothesis leads to the prediction that flies in poor condition should be recaptured earlier. In two out of three of Hoffmann and Turelli's relevant experiments, flies which had been starved before release were recaptured significantly earlier than unstarved controls, and the third experiment showed the same trend.

In experiment 1 , mortality and dispersal data both indicate that hemlock flies were in poorer condition than the deciduous flies. Hemlock flies were recaptured significantly earlier, as indicated by the presence of the [TC] interaction in the simplest model for this experiment. Counts of unmarked flies captured suggest that flies were slightly more abundant in the hemlock area. This is the reverse of what we would expect, based on the mortality of flies in captivity. Consequently, we regard our anaesthetisation and counting of flies before release as the source of any differences in the condition of the two groups, since each group was counted by a different person. 
Table 6 Correlations of $\Delta$ values over all experiments. Lower number is the sample size for the correlation

\begin{tabular}{lllll}
\hline & $\begin{array}{l}\text { affinis/ } \\
\text { algonquin } \\
\text { females }\end{array}$ & $\begin{array}{l}\text { algonquin } \\
\text { males }\end{array}$ & $\begin{array}{l}\text { athabasca } \\
\text { males }\end{array}$ & $\begin{array}{l}\text { athabasca } \\
\text { females }\end{array}$ \\
\hline affinis males & $0.900^{* *}$ & -0.645 & $0 \cdot 838$ & 0.976 \\
& 7 & 3 & 5 & 3 \\
affinis/algonquin & & -0.441 & $0 \cdot 950^{*}$ & 0.894 \\
females & 3 & 5 & 3 \\
algonquin males & & & $-0 \cdot 750$ & -0.796 \\
& & 3 & 3 \\
athabasca males & & & & $0.997^{*}$ \\
& & & & 3 \\
\hline
\end{tabular}

${ }^{*} P<0.05,{ }^{* *} P<0.01$.

This suggests that the magnitude of the time of capture by capture site interaction is a useful indicator of differences in condition of flies from different areas. In none of our other experiments was this term significant. The $G$ values associated with the [TC] interaction for experiments 2,3 twice-marked flies, 3 once-marked flies, 4 , and the wild pine experiment are $3 \cdot 26,0 \cdot 10,0 \cdot 49,2 \cdot 12$, and 0.33 respectively. This range of $G$ values does not suggest any tendency towards an interaction. In none of these experiments were flies anaesthetised and counted.

As another way to test for condition effects, we can ask whether groups of flies which differed in their time of recapture also tended to differ in the probability of choosing habitats. We have calculated a time of recapture index $\left(\Delta_{t}\right)$, analogous to $\Delta$, which quantifies this. $\Delta_{t}$ is equal to the absolute value of $P_{1 \mid X}-P_{1 \mid Y}$, or the probability that a recaptured fly from habitat $X$ is recaptured in period 1 minus the probability that a recaptured fly from habitat $Y$ is recaptured in period 1 . According to the physiological condition hypothesis, $\Delta$ should be positively correlated with $\Delta_{t}$. For experiment 1 the two indices are highly correlated $(r=0.99,3 \mathrm{df}$, $P<0.005)$, but they are uncorrelated for the other experiments using wild caught flies $(r=-0.33$, $14 \mathrm{df}, P<0.5)$. If biased treatment of the flies in captivity was causing one group of flies to be in poor condition, the sign of the $\Delta$ values would be arbitrary, and the absolute value of $\Delta$ should be correlated with $\Delta_{t}$. Excluding experiment 1, this correlation is $-0 \cdot 11$.

A possible source of bias in experiments of this type is the inappropriate lumping of data in contingency tables. For example, if we lump athabasca males and females over the hemlock vs. deciduous experiments, we find significant negative habitat choice with a $\Delta$ value of -0.07 , although in the unlumped data there is no hint of negative choice for athabasca flies. We have sought to avoid such lumping wherever possible. Only in the case of affinis/algonquin females was it necessary. This class of flies never showed any habitat choice, and removal of these data does not change the results of any experiment.

If we disregard experiment 1 , we have still obtained consistent evidence that affinis males show habitat choice, but at a very low level. We have no direct evidence of habitat choice in any of the other classes of flies, but none of them were ever significantly different from affinis males in their capture site by recapture site interactions, as shown by the lack of [SCR] interactions in table 5. Collectively, all the flies showed significant choice in experiment 4 . The lack of significant $\Delta$ values in the other classes of flies may simply reflect smaller sample sizes. The high correlations of $\Delta$ values suggests that the flies may be responding to the same factors. Thus, it is possible that all the flies exhibit habitat choice at the same low level as affinis males.

Previous positive reports of habitat choice in the obscura group, summarised by Turelli et al. (1984), had an average $\Delta$ value of $0 \cdot 245$. Excluding experiment 1 , only two out of 22 estimates of $\Delta$ exceeded $0 \cdot 245$, and in 13 cases our $\Delta$ values were significantly less than this. There can be little doubt that the species we studied are choosing at a far lower level in general.

The average $\Delta$ value for wild affinis males is 0.076 , so flies were 7.6 per cent more likely to return to the habitat in which they were captured than the alternative area. Given the small size of the hemlock patches and pine plantation we studied, it seems unlikely that genetic differentiation is greatly facilitated by this level of fidelity. With the vagility of these species, even a short 
interruption in choice behavior, due to, for instance, a shortage of resources in one habitat, would quickly break down any differentiation not maintained by strong selection.

Theoretical support for this assertion is provided by Slatkin's (1973) analysis of gene flow in one dimension across a boundary between selective regimes for a one locus, two allele, additive fitness model. If we consider the ecotones between habitats in our study as such a boundary, $\Delta$ is equivalent to Slatkin's barrier parameter, $k$, the proportion of individuals reaching the boundary that turn back. He demonstrated that the product of $1-k$ and the change in gene frequency at the boundary will be on the order of $s / 2$, where $s$ is the change in relative fitness of the two homozygotes at the boundary. Thus, the effect of a barrier to gene flow will be small, unless $1-k$ is of the same order as $s / 2$. For reasonable selective differences between habitats, $1-k$ would have to be much less than 1 in order to make much difference. Using our data for affinis males, $1-k$ is 0.924 , obviously quite close to 1 .

One test for the heritability of habitat preference showed that lab-reared flies had significantly different preferences than the parental generation. Taylor and Powell (1978) did a similar experiment, also with negative results, even though wild caught flies were choosing at a much higher level in their experiments. Nevertheless, these experiments are very weak tests for heritability of preference. While we can say the lab reared flies did not show the habitat preference of their parents, this can mean any of several things. The preference may be only weakly heritable, or require experience to be expressed, or the stimuli to which the parental generation responded may have changed between the two experiments. It is also possible that preferences are not heritable and flies become conditioned to prefer habitats where they mature or spend time.

Studies of this kind cannot demonstrate that different resource preferences do not exist. For example, we would not find discriminatory behaviour related to oviposition sites, which could have important genetic consequences (Jaenike, 1982), unless the abundance of different types of sites varied across habitats as we defined them. Clearly the next step for those interested in population structure of Drosophila in relation to their ecology must be to identify the environmental stimuli flies perceive, and to quantify non-random behaviour in relation to these stimuli. Unfortunately, this has proved very difficult in the obscura group.
The low level of choice observed in our experiments, as well as the largely negative results of Turelli et al. (1984), and Atkinson and Miller (1980) suggest that the high levels of choice observed by Taylor and Powell (1978), Kekic et al. (1980), and Shorrocks and Nigro (1981) may be unusual. In addition, the results of Hoffmann and Turelli (1985), which suggest the potential for spurious results in experiments of this kind, are further cause to be cautious about the evolutionary significance of habitat choice in Drosophila.

Acknowledgements We thank W. Eanes for his advice and support in all aspects of this work; D. Barney, B. Bingham, A. Pugliese, C. Thrash, and R. S. Unnasch for enthusiastic assistance in the field; and three reviewers for their comments. This work was supported by two Summer Research Fellowships from the Edmund Niles Huyck Preserve to the authors, and by NSF grant BSR 8340664 to W. Eanes. This is contribution number 562 from the Program in Ecology and Evolution at SUNY Stony Brook.

\section{REFERENCES}

ATKINSON, W. D. AND MILLER, J. A. 1980. Lack of habitat choice in a natural population of Drosophila subobscura. Heredity, 44, 193-199.

BISHOP, Y. M. M., FIENBERG, S. E. AND HOLLAND, P. W. 1975. Discrete Multivariate Analysis: Theory and Practice, MIT Press, Cambridge, Mass.

CRUMPACKER, D. W. AND Williams, J. S. 1973. Density, dispersion, and population structure in Drosophila pseudoobscura. Ecol. Mon., 43, 499-538.

HEY, J. AND HOULE, D. 1985. Rearing Drosophila athabasca. Drosophila Inform. Serv., 61, 192-193.

HOFFMANN, A. A. AND TURELLI, M. 1985. Distribution of Drosophila melanogaster on alternative resources: effects of experience and stavation. Am. Nat., 126, 662-679.

JAENIKE, J. 1982. Environmental modification of oviposition behavior in Drosophila. Am. Nat., 119, 784-802.

JAENIKE, J., MILLER, D. D., AND SELANDER, R. K. 1978. Electrophoretic differences among semispecies of Drosophila athabasca. Drosophila Inform. Serv., 53, 153-154.

JOHNSON, D. L. E. 1978. Genetic differentiation in two members of the Drosophila athabasca complex. Evolution, 32, 798811.

JOHNSON, D. L. E. 1985. Genetic differentiation of the Drosophila athabasca complex. Evolution, 39, 467-472.

KEKIC, V., TAYLOR, C. E. AND AND JELKOVIC, M. 1980. Habitat choice and resource specialization by Drosophila subobscura. Genetika, 12, 219-225.

MILlER, D. D. AND WESTPHAL, N. J. 1967. Further evidence on sexual isolation within Drosophila athabasca. Evolution, $21,479-492$.

SAS INSTITUTE, INC. 1985. SAS User's Guide: Statistics, Version 5 Edition. SAS Institute, Cary, NC.

SHORROCKS, B. AND NIGRO, L. 1981. Microdistribution and habitat selection in Drosophila subobscura Collin. Biol. $J$. Linn. Soc., 16, 293-301.

SLATKIN, M. 1973. Gene flow and selection in a cline. Genetics, $75,733-756$. 
STALKER, H. D. 1976. Chromosome studies in wild populations of D. melanogaster. Genetics, 83, 887-894.

TAYLOR, C. E. AND POWELL, J. R. 1977. Microgeographic differentiation of chromosomal and enzyme polymorphisms in Drosophila persimilis. Genetics, 85, 681-695.
TAYLOR, C. E. AND POWELl, J. R. 1978. Habitat choice in natural populations of Drosophila. Oecologia, 37, 69-75.

TURRElli, M., COYNE, J. A., AND PROUT, T. 1984. Resource choice in orchard populations of Drosophila. Biol. J. Linn. Soc., 22, 95-106. 